\title{
Bacillus thuringiensis var. israelensis como alternativa para o controle po- pulacional de Aedes aegypti (Linnaeus, 1762) (Diptera: Culicidae)
}

\section{Bacillus thuringiensis var. israelensis as an alternative to population control of Aedes aegypti} (Linnaeus, 1762) (Diptera: Culicidae)

Junir Antonio Lutinski ${ }^{1}$, Adriana Gracietti Kuczmainski ${ }^{1}$, Suiane de Quadros ${ }^{1}$, Maria Assunta Busato ${ }^{1}$, Cleidenara Maria Mohr Weirich ${ }^{2}$, Anderson Malgueiro ${ }^{3}$ e Flávio Roberto Mello Garcia ${ }^{4}$

${ }^{1}$ Universidade Comunitária da Região de Chapecó, Chapecó, SC, Brasil junir@unochapeco.edu.br; adri_gtt@hotmail.com; assunta@unochapeco.edu.br; suiane@unochapeco.edu.br

${ }^{2}$ Secretaria de Saúde do município de Chapecó, SC, Brasil.

cleidenaraweirich@outlook.com

${ }^{3}$ Serviço Nacional de Aprendizagem Comercial (SENAC), São José, SC, Brasil malgueiro@sc.senac.br

${ }^{4}$ Universidade Federal de Pelotas. Pelotas, RS - Brasil flavio.garcia@ufpel.edu.br

\section{Resumo}

Dengue, chikungunya e zika estão entre os principais desafios à saúde pública no mundo. Na ausência de vacinas, a única alternativa conhecida para a prevenção é o controle do mosquito transmissor. Dentre os métodos de controle, o biológico utilizando cepas do Bacillus thuringiensis israelensis (Bti) vem se destacando pela sua eficiência e segurança na aplicação. Este estudo objetivou avaliar a eficiencia do Bti para o controle populacional do mosquito Aedes aegypti em depósitos de ferros-velhos e reciclagens do município de Chapecó, Santa Catarina. Foram realizadas sete aplicações de Bti, uma a cada 21 dias, em três ferros-velhos e três de centros de reciclagem, no periodo de agosto a dezembro de 2014. Foram tomados os números mensais de focos e de ovos e larvas de A. aegypti dos estabelecimentos teste e comparados com os resultados obtidos em ferros-velhos e reciclagens controle. Foi observada uma redução de 89,6\% no número de focos, de ovos e de larvas do mosquito nos estabelecimentos que receberam o tratamento com Bti em relação aos estabelecimentos controle. A infestação ocorreu dois meses mais cedo nos estabelecimentos que não receberam tratamento. O Bti apresentou eficiência no controle populacional do mosquito A. aegypti em ferros-velhos e centros de reciclagens nas condições testadas e pode ser uma alternativa para a prevenção à dengue, chikungunya e zika vírus.

Palavras-chave: Chikungunya; Controle biológico; Dengue; Prevenção; Zika vírus

\section{Abstract}

Dengue, chikungunya and zika are among the major problems to public health problem in the world. In the absence of vaccine, the only known alternative to prevention is to control the mosquito. Among the methods of control, using biological strains of Bacillus thuringiensis israelensis (Bti) has stood out for its efficiency and security in the application. This study aimed to evaluate the efficiency of Bti to control the population of the Aedes aegypti mosquito in junkyards and recycling centers of Chapeco, Santa Catarina. Seven applications of Bti were conducted once every 21 days, three junkyards and three recycling centers, from August to December 2014. Was used wettable powder, soluble in water and applied at a concentration of 800 grams per hectare according to the manufacturer's technical specifications. The monthly number of larvae and of eggs and larvae of A. aegypti were recorded and compared with the results obtained in junkyards and recycling control. It was observed a reduction of $89.6 \%$ in the number of eggs and mosquito larvae in establishments that received treatment with Bti, compared to the establishments control. The infestation occurred two months earlier in establishments that did not receive treatment. The Bti was efficient in the mosquito A. aegypti population control in junkyards and recycling centers in tested conditions. It is presented as an alternative for the prevention of dengue, chikungunya and zika virus.

Keywords: Chikungunya; Biological control; Dengue; Prevention; Zika virus 


\section{Introdução}

Entre as doenças emergentes, a febre chikungunya e zika vírus e reemergentes, a dengue, vêm sendo considerados entre os principais desafios para a saúde pública em muitas regiões do mundo, incluindo o Brasil. O atual quadro epidemiológico dessas doenças no país se caracteriza pela tendência crescente de casos e pela ampla distribuição e infestação do mosquito transmissor, Aedes aegypti (Linnaeus, 1762) (BRAGA; VALLE, 2007; BRASIL, 2009; TEIXEIRA; BARRETO, 2009). Na ausência de vacina e medicamentos, o controle da população do mosquito vetor é a forma conhecida de prevenir e controlar a doença (WHO, 1980; RODRIGUEZ et al., 2005; HARRIS; RAJATILEKA; RANSON, 2010).

No Brasil, os cenários socioambiental e climático são favoráveis à expansão do mosquito A. aegypti. A urbanização acelerada, os hábitos da população, as lacunas infraestruturais como deficiências de saneamento básico e a concentração de resíduos sólidos sem destino adequado proporcionam a oferta abundante de criadouros para o mosquito em áreas urbanas. As condições climáticas de temperatura e pluviosidade também são favoráveis (TAUIL, 2002) e estão sendo agravadas pelo processo de aquecimento global que vem proporcionando condições para a infestação em regiões outrora livres do vetor (RIBACK, 2009; NEIS; BALSAN; MOURA, 2013; ARAÚJO; CÂNDIDO; DANTAS, 2014).

Frente à complexidade do controle dessas doenças e tendo em vista os desafios enfrentados, o Ministério da Saúde vem articulando políticas públicas de prevenção. Estas, tendo como foco na descentralização e intersetorialidade das ações de controle por meio da integração entre o serviço e comunidade com ênfase no saneamento ambiental (BRASIL, 2009; ARAÚJO; CÂNDIDO; DANTAS, 2014). Entre as estratégias de combate à dengue, chikungunya e zika vírus encontra-se o controle vetorial (BRASIL, 2009), podendo ser realizado a partir de diferentes métodos: controle mecânico visando à destruição ou a destinação adequada de criadouros; controle legal que consiste na aplicação de normas e instrumentos previstos na legislação; controle químico utilizando substâncias para reduzir a população do vetor nas fases larvária e adulta; e o controle biológico, o qual se apresenta como uma alternativa ao utilizar agentes biológicos (LIMA; MELO; VALLE, 2005).

Dentre as alternativas disponíveis para o controle biológico, o uso de biolarvicidas à base de Bacillus thuringiensis vem se destacando no cenário mundial. Primeiramente pela eficácia no controle do A. aegypti, uma vez que o Bacillus thuringiensis israelensis (Bti) apresenta importante propriedade larvicida, ao produzir endotoxinas proteicas que, quando ingeridas pelas larvas, provocam sua morte (PONTES et al., 2005; BRASIL, 2009; BOYCE et al., 2013). Além das vantagens relacionadas à seletividade do produto, não possuindo efeito tóxico aos humanos e animais (PETRY et al., 2004), até o momento não foi observado o desenvolvimento de resistência (GLARE; O’CALLAGHAN, 1998).

Este estudo foi realizado em Chapecó, Santa Catarina, cuja localização geográfica do município (divisa com o estado do Rio Grande do Sul e a proximidade com a Argentina e Paraguai) apresenta-se como região de grande fluxo de cargas nacionais e internacionais. Além disso, o constante trânsito de pessoas pelo município e o número de estudantes vindos de outros estados, aliados à elevada infestação registrada na última década, geram preocupação constante para os gestores e profissionais de saúde frente ao risco de ocorrência de epidemias (SANTA CATARINA, 2014).

O município conta atualmente com, aproximadamente, 350 pontos estratégicos (PE) cadastrados pelo Programa Municipal de Controle da Dengue (PCD), destes, cerca de 50 reciclagens, 100 ferros-velhos e depósitos de sucata. O A. aegypti encontra condições favoráveis para a sua proliferação nestes ambientes (SANTA CATARINA, 2014) onde tem ficado praticamente imune aos métodos mecânicos e químicos de controle. Por serem numerosos e de rotatividade periódica, os potenciais criadouros existentes nestes tipos de estabelecimentos não são passíveis de destruição mecânica e os Agentes de Combate às Endemias 
não têm acesso a todos os criadouros para efetuar o controle químico com larvicida.

Diante do exposto este trabalho teve como objetivo avaliar a eficiência do Bacillus thuringiensis var. israelenses (Bti) para o controle populacional do mosquito A. aegypti em depósitos ferros-velhos e reciclagens do município de Chapecó, Santa Catarina.

\section{Material e método}

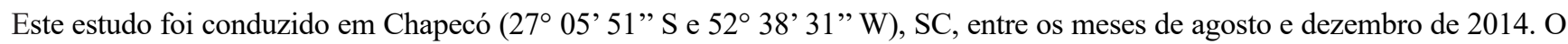
município se destaca pelo acelerado crescimento populacional, contando com cerca de 202.000 habitantes segundo dados do Instituto Brasileiro de Geografia e Estatística (IBGE, 2014). O clima da região é do tipo superúmido mesotérmico subtropical úmido, sem estação seca definida, com geadas severas frequentes e com distribuição regular da pluviosidade (KÖPPEN, 1948).

Foram selecionados seis estabelecimentos de ferros-velhos e seis de reciclagens de resíduos que apresentaram focos (recipientes contendo larvas ou ovos) de A. aegypti de forma regular (semanal) de janeiro a abril de 2014. Para a escolha, foi consultado o banco de dados do Programa Municipal de Controle da Dengue (PCD). A distância mínima entre os estabelecimentos teste e controle foi de 500 metros e as condições climáticas (pluviosidade e temperatura) foram idênticas em cada caso. Como critério de inclusão, foi definido também que os estabelecimentos deveriam conter área de depósito igual ou superior a 400 $\mathrm{m}^{2}$ e manter peças de carro ou sucatas (estabelecimentos de ferros-velhos) ou resíduos sólidos recicláveis (estabelecimentos de reciclagens) a céu aberto. De forma aleatória, três dos ferros-velhos e três reciclagens (teste) foram escolhidos para receber aplicações de Bti enquanto os demais (controle) receberam o monitoramento tecnicamente recomendado pelo Ministério da Saúde (BRASIL, 2001) e pela Diretoria de Vigilância Epidemiológica do Estado de Santa Catarina (SANTA CATARINA, 2014): visitas quinzenais com a eliminação de criadouros e tratamento dos depósitos de água com o ingrediente ativo Temefós $500 \mathrm{CE}$, em uma concentração de $1 \mathrm{~g} / 10$ litros de água.

Um lote de Bacillus thuringiensis var. israelenses Vectobac $\mathrm{WG}{ }^{\circledR}$ foi obtido junto a um fornecedor regional de produtos agropecuários. A formulação do produto foi de pó molhável o qual foi solubilizado em água e aplicado em uma concentração de 800 gramas por hectare, de acordo com as recomendações técnicas do fabricante. Foram realizadas sete aplicações entre os meses de agosto a dezembro de 2014 obedecendo a um intervalo de 21 dias entre uma aplicação e outra. Foi utilizado pulverizador costal motorizado para as aplicações, regulado para uma vazão de $400 \mathrm{ml}$ por minuto e um alcance de 10 metros. O período escolhido para a realização do estudo corresponde ao final do inverno e a primavera, estações em que se observa o recrudescimento da infestação por $A$. aegypti nos municípios da região sul do Brasil.

Como variáveis respostas, foram tomados os números mensais de focos e de ovos e larvas de $A$. aegypti amostrados nos estabelecimentos teste e controle. Em cada estabelecimento (teste e controle) foi instalada uma armadilha do tipo ovitrampa, uma semana antes do início da aplicação do Bti e do início do monitoramento. Estas foram inspecionadas semanalmente durante todo o período do estudo. Também foram realizadas visitas de inspeção larvária (PE), quinzenalmente. As ovitrampas utilizadas consistem em um recipiente de plástico preto com capacidade para $1000 \mathrm{~mL}$, contendo em seu interior uma solução atrativa à base de feno fermentado e uma palheta de Eucatex ${ }^{\circledR}$. A solução das ovitrampas foi substituída semanalmente. As palhetas recolhidas e as larvas amostradas durante as inspeções foram encaminhadas para o Laboratório Municipal de Entomologia, onde foram respectivamente examinadas quanto à presença de ovos e identificadas. Cada palheta contendo ovos ou amostra positiva de larvas caracterizou um foco. Foi realizada uma soma mensal da contagem dos ovos e das larvas em cada estabelecimento (teste e controle). 


\subsection{Análises estatísticas}

Os números mensais de focos, ovos e larvas de $A$. aegypti foram tabulados e comparados segundo suas frequências mensais e totais. Foi realizada análise de variância (ANOVA) sobre o número de ovos e de larvas amostradas mensalmente. Este teste possibilitou a comparação entre as médias obtidas para os estabelecimentos teste e controle. As frequências foram previamente transformadas em escala logarítmica para atender à premissa de normalidade dos dados. As médias também foram agrupadas e comparadas pelo teste de Duncan em nível de 5\% de probabilidade de erro. O programa estatístico utilizado foi o SANEST (ZONTA; MACHADO; SILVEIRA JUNIOR, 1984).

\section{Resultados}

Foi observada redução significativa $(\mathrm{F}=18,2 ; \mathrm{p}<0,01)$ no número de focos de $A$. aegypti nos estabelecimentos que receberam o tratamento com Bti em relação àqueles que receberam o monitoramento e tratamento em uso pelo PCD. Os ferros-velhos controle apresentaram cinco vezes mais focos $(n=15)$ comparados àqueles que receberam as aplicações $(n=3)$. Nas reciclagens a redução foi total, sendo que nenhum foco foi encontrado nas reciclagens teste comparado às reciclagens controle $(\mathrm{n}=14)($ Figura 1$)$.

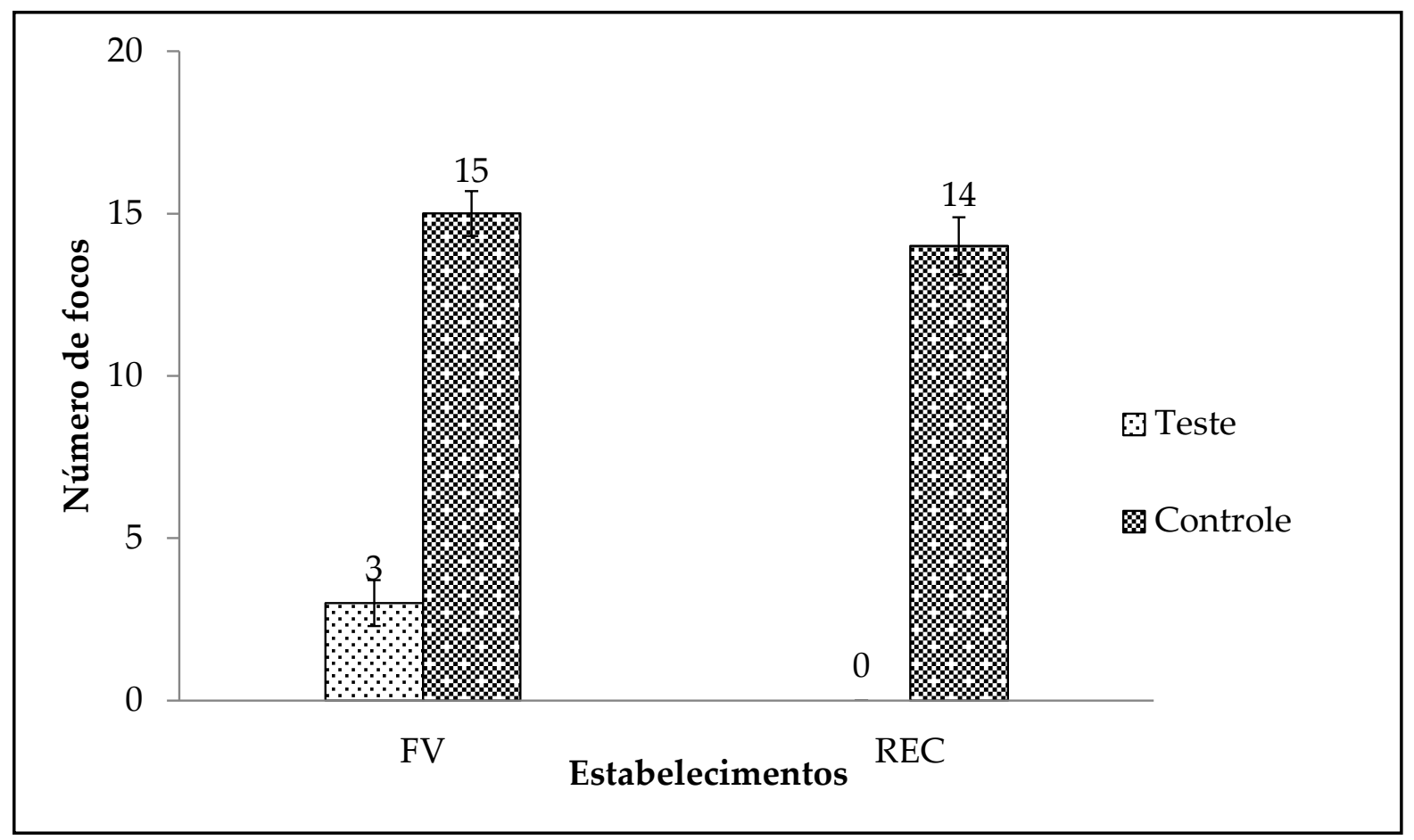

Figura 1 - Comparativo entre ferros-velhos (FV) e reciclagens (REC), segundo os focos de $A$. aegypti que receberam aplicações de Bti (teste) e que receberam o acompanhamento ou tratamento adotado pelo Programa Municipal de Prevenção à Dengue (controle), de agosto a dezembro de 2014, no município de Chapecó, Santa Catarina. As barras verticais indicam o erro padrão da média

A contagem total de ovos e de larvas de $A$. aegypti apresentou um padrão de amplitude maior do que aquele verificado no número de focos. Após a aplicação do Bti, os ferros-velhos controle apresentaram 9,6 vezes mais larvas do que os ferros-velhos teste. Enquanto que nas reciclagens teste não foi encontrada nenhuma larva ou palheta com ovos, nas reciclagens controle foram registradas 305 ao final do estudo (Figura 2). 


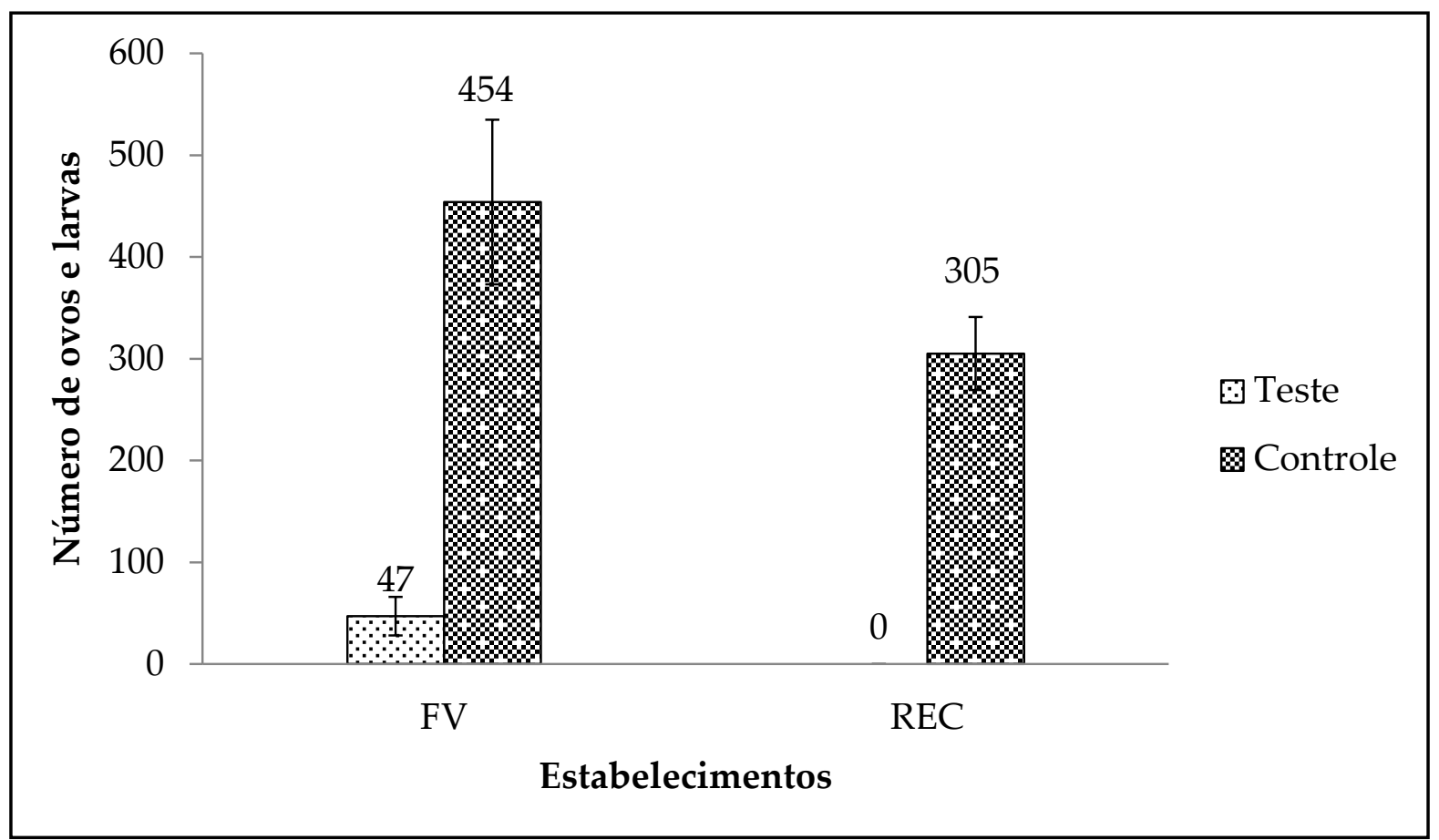

Figura 2 - Comparativo entre ferros-velhos (FV) e reciclagens (REC), segundo o número de ovos e larvas de $A$. aegypti, que receberam aplicações de Bti (teste) ou que receberam o acompanhamento e tratamento adotado pelo Programa Municipal de Prevenção à Dengue (controle), de agosto a dezembro de 2014, no município de Chapecó, Santa Catarina. As barras verticais indicam o erro padrão da média

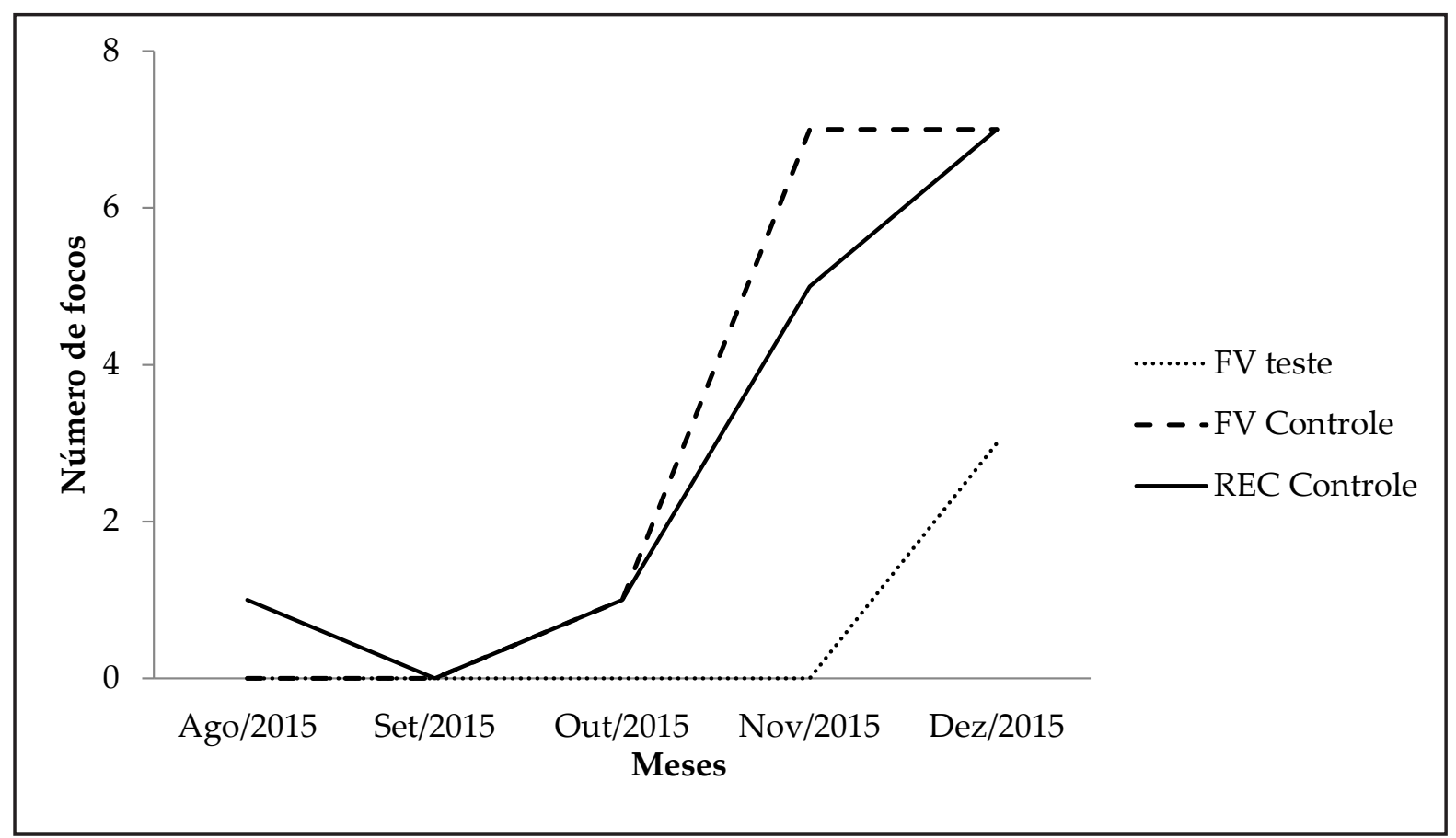

Figura 3 - Comparativo da evolução mensal do número de focos de A. aegypti entre ferros-velhos (FV) e reciclagens (REC), que receberam aplicações de Bti (teste) ou que receberam o acompanhamento e tratamento adotado pelo Programa Municipal de Prevenção à Dengue (controle), de agosto a dezembro de 2014, no município de Chapecó, Santa Catarina 
Considerando o período avaliado como de recrudescimento da infestação, observou-se que nos estabelecimentos controle, a presença de ovos e de larvas de A. aegypti ocorreu dois meses mais cedo do que nos estabelecimentos que receberam o Bti. Nas reciclagens teste não foi observada a presença de $A$. aegypti enquanto estavam recebendo aplicações do biolarvicida enquanto que nas reciclagens controle foram obtidas amostras positivas ainda no mês de agosto. Nos ferros-velhos teste, a presença do mosquito só foi registrada no último mês (dezembro) enquanto nos ferros-velhos controle, foi detectado no mês de setembro (Figura 3).

Foram encontradas diferenças entre as médias da contagem de ovos e larvas de $A$. aegypti entre os estabelecimentos que receberam aplicações de Bti e os estabelecimentos controle. O mesmo foi verificado entre os meses do período de realização do estudo (Tabela 1).

Tabela 1 - Súmula da análise de variância comparando o número mensal de ovos e larvas de $A$. aegypti em ferros-velhos e reciclagens que receberam aplicações de Bti ou que receberam o acompanhamento e tratamento

adotado pelo Programa Municipal de Prevenção à Dengue, de agosto a dezembro de 2014, no município de

Chapecó, Santa Catarina. GL = graus de liberdade; $\mathrm{QM}=$ quadrados médios; $\mathrm{E}^{*} \mathrm{M}=$ Interação entre os fatores estabelecimentos e meses; ${ }^{*}$ significância estatística $(\mathrm{p})$

\begin{tabular}{lcccc}
\hline Causas da variação & GL & QM & F Valor & p \\
\hline Estabelecimentos & 3 & 11,3 & 18,2 & $<0,01 *$ \\
\hline Meses & 4 & 14,4 & 23,2 & $<0,01 *$ \\
\hline Interação E*M & 12 & 3,1 & 4,9 & $<0,01 *$ \\
\hline Resíduo & 40 & 0,6 & & \\
\hline Total & 59 & 153,5 & & \\
\hline
\end{tabular}

Os ferros-velhos e reciclagens controle não diferiram entre si quanto à contagem média mensal de ovos e de larvas, contudo, diferiram significativamente $(F=23,2 ; p<0,01)$ dos ferros-velhos teste e das reciclagens teste (Figura 4).

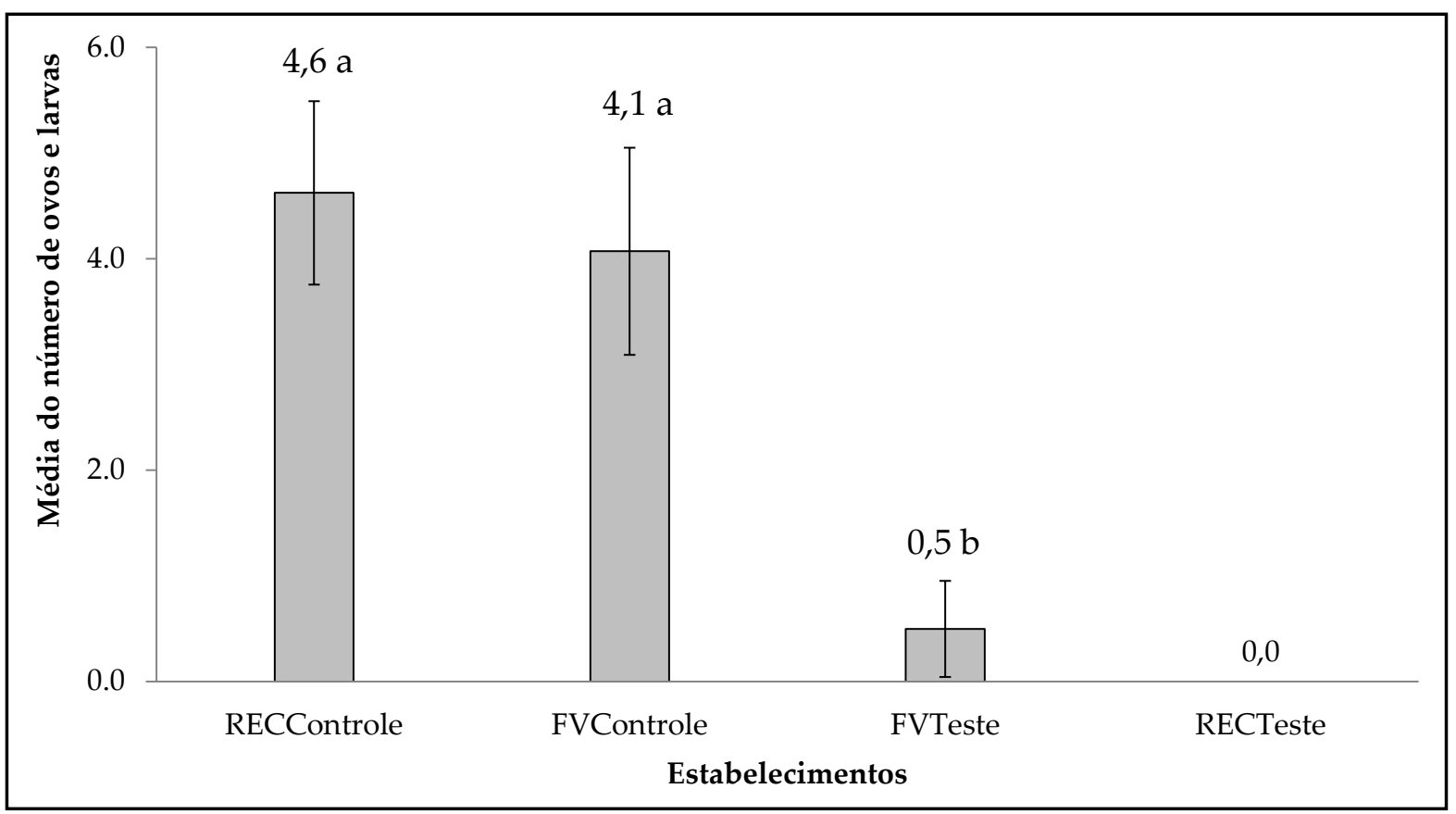

Figura 4. Comparativo, segundo as médias do número mensal de ovos e larvas de $A$. aegypti, dos entre ferros-velhos (FV) e reciclagens (REC), que receberam aplicações de Bti (Teste) ou que receberam o acompanhamento e tratamento adotado pelo Programa Municipal de Prevenção à Dengue (Controle), de agosto a dezembro de 2014, no município de Chapecó, Santa Catarina. As barras verticais indicam o erro padrão da média. As letras "a" e "b" que seguem as médias indicam a diferença segundo Duncan em nível de 5\% de probabilidade de erro. 


\section{Discussão}

O Bti apresentou eficiência no controle populacional do mosquito A. aegypti em depósitos de ferros-velhos e reciclagens do município de Chapecó, nas condições testadas. Reduziu de forma significativa o número de focos, de ovos e de larvas encontrados nos estabelecimentos que receberam aplicações do produto em relação aos estabelecimentos tidos como controle. As aplicações do produto também fizeram com que o recrudescimento da infestação nos ferros-velhos ocorresse mais tardiamente.

A redução da infestação verificada neste estudo corrobora os resultados obtidos por Boyce et al. (2013) que ao avaliarem a literatura sobre a eficácia do Bti como agente para o controle de vetores, analisaram 14 estudos onde, em 12 foi constatada a redução pós-intervenção na massa de fases imaturas dos vetores em comparação com o respectivo grupo controle. O uso do Bti apresenta-se como uma alternativa ao uso dos agentes químicos sintéticos no controle populacional de A. aegypti, ao demonstrar-se como um bioinseticida eficaz e seletivo, não impactando sobre espécies não alvo e adaptando-se ao contexto de urbanização vivenciado na atualidade (POLANCZYK; GARCIA; ALVES, 2003).

A aplicação da formulação testada, através da pulverização, permite que gotículas do biolarvicida alcance os locais de acúmulo de água onde o A. aegypti pode ser encontrado (BATRA; MITTAL; ADAKT, 2000) e permaneça ativo por até três semanas, mesmo com ausência de chuva. Esta formulação atende às necessidades do PCD diante da complexidade enfrentada para o controle vetorial em ferros-velhos e reciclagens existentes no município. Dado que o acesso aos criadouros é inviabilizado pelo grande volume de materiais, a eficiência do Bti pode auxiliar pelo alcance da pulverização até os depósitos com água e pela deposição das gotículas do produto sobre os materiais secos que, ao receberem a chuva nos dias subsequentes, escorre e se acumula nos depósitos de água que se formam sob o acumulado de peças, sucatas e resíduos sólidos recicláveis. O volume menor de materiais que se acumulam nas reciclagens em relação aos ferros velhos pode explicar a maior ação do Bti nesses estabelecimentos, já que nas reciclagens teste não foi encontrado nenhum foco, no período avaliado.

O atual contexto de controle da dengue, chikungunya e zika vírus exige uma reflexão do cenário social e urbano da realidade vivenciada. Os determinantes envolvidos na propagação destas doenças, tais como a precariedade dos processos de urbanização, acabam por favorecer a disseminação do vetor da doença além de dificultar a atuação em seu controle (DONALISIO; GLASSER, 2002). No caso dos ferros-velhos, o grande volume de peças e sucatas a céu aberto tem representado a principal causa da manutenção e da reinfestação anual da cidade após o inverno. Na maioria dos casos a cobertura destes materiais esbarra em questões de viabilidade técnica e legal. No caso das reciclagens, o cenário é ainda mais complexo já que desafios de ordem social, econômica e ambiental impossibilitam soluções definitivas como a cobertura dos materiais. Neste contexto, os resultados obtidos neste estudo apontam o uso do Bti como uma possibilidade real para o controle vetorial nestes espaços até que soluções definitivas possam ser colocadas em prática.

Além das evidências da ligação entre urbanização e a disseminação da dengue, chikungunya e zika vírus, a grande capacidade de adaptação do vetor em áreas urbanas e densamente povoadas acaba por potencializar a situação de vulnerabilidade às doenças (ARAÚJO et al., 2013). Segundo Donalísio e Glasser (2002), a disseminação vem acompanhando o homem no decorrer da história, em suas migrações, deslocamentos e aglomerações. Considerando o crescente desafio que o controle de vetores representa em áreas urbanas é urgente a necessidade de produtos seguros, eficientes e que atendam as peculiaridades locais (ARAÚJO et al., 2013; BOYCE et al., 2013). O desenvolvimento econômico experimentado pelo Brasil na última década é bem evidenciado no município de Chapecó onde o comércio de veículos e peças cresceu substancialmente levando ao surgimento de dezenas de pátios com acúmulo de veículos em desuso. Quanto à gestão dos resídios sólidos urbanos, a ad- 
ministração pública minicipal investiu nos últimos cinco anos, na construção de barracões para a reciclagem, contudo, ainda há famílias não atendidas que têm na reciclagem a sua fonte de subseitência e que não contam com espaços cobertos para o armazenamento do material.

Dentre os inseticidas recomendados pelo Ministério da Saúde (BRASIL, 2001) o Bti é mencionado como uma alternativa (BECKER, 1997; BROWN et al., 1998). No entanto, o seu uso vem sendo recomendado de forma restrita à situações em que já se observou resistência das populações do vetor aos inseticidas químicos sintéticos em uso (LIMA; MELO; VALLE, 2005; LIMA et al., 2006; MACORIS et al., 2014). De maneira geral, ainda são usados carbamatos e piretróides (FORATTINI, 2002) nos programas de controle vetorial por todo o Brasil. Um dos fatores que tem impedido o uso do Bti pelos programas locais de prevenção à dengue é que os municípios são abastecidos pelos produtos determinados e distribuídos pelo Ministério da Saúde e geralmente não contam com recursos financeiros próprios para adquirir produtos que melhor atendam às suas necessidades locais. Este cenário conduziu à realidade atual do conhecimento e do uso restrito do Bti nos programas de Prevenção à Dengue em contraste com os inúmeros estudos que apontam a eficiência de diferentes cepas do produto (CHUI; WONG; TSOI, 1995; VILARINHOS et al., 1998; BECKER, 2000; DELÉCLUSE; PÉREZ; BERRY, 2000; RITCHIE; RAPLEY; BENJAMIN, 2010).

\section{Conclusão}

A partir da complexidade que o controle populacional do mosquito A. aegypti representa no município de Chapecó e a sua realidade de grandes depósitos de sucatas, ferros-velhos e resíduos sólidos recicláveis a céu aberto, o Bti apresentou expressiva eficiência nos estabelecimentos testados quando comparado aos estabelecimentos controle. A realidade destes estabelecimentos é facilmente constatada em outras cidades do estado e do Brasil e os resultados apontados por este estudo podem conduzir para uma solução paliativa, porém eficiente para estes locais até que soluções definitivas sejam possíveis de serem implantadas. Existem dispositivos legais que obrigam proprietários de ferros-velhos a cobrir e manter materiais sob cobertura, mas os movimentos para que estas normas e leis tenham efeito são tímidos e pontuais. Recai sobre os profissionais de saúde a responsabilidade por encontrar caminhos e soluções para os desafios locais. Embora a eficiência obtida seja expressiva tanto na redução da infestação como no prolongamento do tempo até o recrudescimento da mesma, os resultados não são definitivos. Sugerimos avaliações adicionais durante o período de máxima infestação (verão), mas consideramos que os resultados obtidos apontam para uma importante possibilidade para o controle vetorial em ferros-velhos e centros de reciclagens.

\section{Agradecimentos}

À Secretaria de Saúde de Chapecó e aos proprietários dos estabelecimentos envolvidos pela permissão para a realização do estudo.

\section{Referências}

ARAÚJO, A. P.; DINIZ, D. F. A.; HELVECIO, E.; BARROS, R. A.; OLIVEIRA, C. M. F.; AYRES, C. F. J.; MELOSANTOS, M. A. V.; REGIS, L. N.; SILVA-FILHA, M. H. N. L. The susceptibility of Aedes aegypti populations displaying Temephos resistance to Bacillus thuringiensis israelensis: a basis for management. Parasites \& Vectors, v. 6, n. 297, p. 1-9, 2013. 
BATRA, C. P.; MITTAL, P. K.; ADAKT, T. Control of Aedes aegypti breeding in desert coolers and tires by use of Bacillus thuringiensis var israelensis formulation. Journal of the Americam Mosquito Control Association, v. 16, n.4, p. 321-323, 2000.

BECKER, N. Microbial control of mosquitoes: management of the upper Rhine mosquito population as a model programme. Parasit Today, v. 13, n. 2, p. 485-487, 1997.

BECKER, N. Bacterial control of vector-mosquitoes and black flies. In: Charles, J. F.; DELÉCLUSE, A.; LeROUX, C. N. Entomopathogenic bacteria: from laboratory to field application. Dordrecht: Kluwer Academic Publishers. p. 383-98. 2000.

BOYCE, R.; LENHART, A.; KROEGER, A.; VELAYUDHAN, R.; ROBERTS, B.; HORSTICK, O. Bacillus thuringiensis israelensis (Bti) for the control of dengue vectors: systematic literature review. Tropical Medicine \& International Health, v. 18, n.5, p. 564-577, 2013.

BRAGA, I. A.; VALLE, D. Aedes aegypti: inseticidas, mecanismos de ação e resistência. Epidemiologia e Serviços de Saúde, v. 16, n. 4, p. 279-293, 2007.

BRASIL. Dengue: Instruções para Pessoal de Combate ao Vetor - Manual de Normas Técnicas. Ministério da Saúde. Fundação Nacional de Saúde, 3. ed., Brasília. 84 p. 2001.

BRASIL. Diretrizes nacionais para prevenção e controle de epidemias de dengue. Ministério da Saúde. Ministério da Saúde. Secretaria de Vigilância em Saúde. Departamento de Vigilância Epidemiológica. 162 p. 2009.

BROWN, M. D.; THOMAS, D.; WATSON, K,; HAY, B. H. Laboratory and field evaluation of efficacy of Vectobac R12AS against Culex sitiens (Diptera: Culicidae) larvae. Journal of Amererican Mosquito Control Association, v. 14, n. 2, p. 183-185, 1998.

CHUI, V. W. D.; WONG, K. W.; TSOI, K. W. Control of mosquito larval (Diptera: Culicidae) using Bti and Teflubenzuron: laboratory evaluation and semi-field test. Environmental International, v. 21, n. 4, p. 433-40, 1995.

DELÉCLUSE, A.; PÉREZ, V. J.; BERRY, C. Vector-active toxins: structure and diversity. In: CHARLES, J. F.; DELÉCLUSE, A.; LeROUX, C. N. Entomopathogenic bacteria: from laboratory to field application. Dordrecht: Kluwer Academic Publishers. p. 101-26. 2000.

DONALISIO, M. R.; GLASSER, C. M. Vigilância entomológica e controle de vetores do dengue. Revista Brasileira de Epidemiologia, v. 5, n. 3, p. 259-279, 2002.

FORATTINI, O. P. Culicidiologia Médica. São Paulo: Edusp, v. 2, 890 p. 2002.

GLARE, T. R.; O'CALLAGHAN, M. Environmental and health impacts of Bacillus thuringiensis israelensis. Report for the Ministry of Health 58 p. 1998.

HARRIS, A.; RAJATILEKA, S.; RANSON, H. Pyrethroid resistance in Aedes aegypti from Grand Cayman. American Journal of Tropical Medicine and Hygiene, v. 83, n.2, p. 277-284, 2010.

IBGE. Instituto Brasileiro de Geografia e Estatística. 2014. Acesso em: http://www.ibge.gov.br/cidadesat/default.php. Acesso em: 10 abr. 2014.

KÖPPEN, W. Climatologia. Fundo de Cultura Econômica, Cidade do México. 325 p. 1948.

LIMA, J. B. P.; MELO, N. V.; VALLE, D. Persistence of Vectobac WDG and Metoprag s-2g against Aedes aegypti larvae using a semi-field bioassay in Rio de Janeiro, Brazil. Revista do Instituto de Medicina Tropical de São Paulo, v. 47, n. 1, p. 7-12, 2005.

LIMA, E. P.; OLIVEIRA FILHO, A. M. O.; LIMA, J. W. O. L.; RAMOS JÚNIOR, A. N.; CAVALCANTI, L. P. G.; PONTES, R. J. S. Resistência do Aedes aegypti ao Temefós em Municípios do Estado do Ceará. Revista da Sociedade Brasileira de Medicina Tropical, v. 39, n. 3, p. 259-263, 2006. 
MACORIS, M. L. G.; ANDRIGHETTI, M. T. M.; WANDERLEY, D. M. V.; RIBOLLA, P. E. M. Impact of insecticide resistance on the field control of Aedes aegypti in the State of São Paulo. Revista da Sociedade Brasileira de Medicina Tropical, v. 47, p. 573-578, 2014.

NEIS, R.; BALSAN, L. A. G.; MOURA, G. L. Análise das políticas públicas de combate à dengue en Contribuciones a las Ciencias Sociales. 2013. Disponível em: www.eumed.net/rev/cccss/24/politicas-publicas-dengue.htm>. Acesso em: 29 mai. 2015.

PETRY, F.; LOZOVEI, A. L.; FERRAZ, M. E.; SANTOS NETO, L. G. Controle integrado de espécies de Simulium (Diptera, Simuliidae) por Bacillus thuringiensis e manejos mecânicos no riacho e nos vertedouros de tanques de piscicultura, Almirante Tamandaré, Paraná, Brasil. Revista Brasileira de Entomologia, v. 48, n. 1, p.127-132, 2004.

POLANCZYK, R. A.; GARCIA, M. O.; ALVES, S. B. Potencial de Bacillus thuringiensis israelenses Berliner no controle de Aedes aegypti. Revista de Saúde Pública, v. 37, n. 6, p. 813-816, 2003.

PONTES, R. J. S.; REGAZZI, A. C. F.; LIMA, J. W. O.; KERR-PONTES, L. R. S. Efeito residual de apresentações comerciais dos larvicidas temefos e Bacillus thuringiensis israelensis sobre larvas de Aedes aegypti em recipientes com renovação de água. Revista da Sociedade Brasileira de Medicina Tropical, v. 38, n. 4, p. 316-321, 2005.

RIBACK, T. I. S. Estratégias adaptativas de Aedes $A$. aegypti e Aedes albopictus em reposta a temperatura e qualidade de criadouros. Botucatu-SP, 91 p. 2009. Tese (Doutorado)-Programa de pós-graduação em Ciências Biológicas, Universidade Estadual Paulista-UNESP.

RITCHIE, S. A.; RAPLEY, L. P.; BENJAMIN, S. Bacillus thuringiensis var. israelensis (Bti) Provides Residual Control of Aedes aegypti in Small Containers. American Journal of Tropical Medicine and Hygiene, v. 82, n. 6, p. 1053-1059, 2010.

RODRIGUEZ, M. M.; BISSET, J. A.; ARMAS, Y.; RAMOS F. Pyrethroid insecticide-resistant strain of Aedes aegypti from Cuba induced by Deltamethrin selection. Journal of the American Mosquito Control Association, v. 21, n. 4, p. 437-445, 2005.

SANTA CATARINA. DIVE. Diretoria de Vigilância Epidemiológica. Secretaria de Estado da Saúde: Superintendência de Vigilância em Saúde. Informações Dengue. 2014. Disponível em: <http://www.dive.sc.gov.br/index.php?option=com content\&task=view\&id=140\&Itemid=151> Acesso em: 10 abr. 2015.

TAUIL, P. L. Aspectos críticos do controle do dengue no Brasil. Cadernos de Saúde Pública, v. 18, n. 3, p. 867-871, 2002.

TEIXEIRA, M. G.; BARRETO, M. L. Diagnosis and management of dengue. BMJ, 339:b4338, 2009.

VILARINHOS, P. T. R.; DIAS, J. M. C. S.; ANDRADE, C. F. S.; ARAÚJO-COUTINHO, C. J. P. C. Uso de bactérias para o controle de culicídeos e simulídeos. In: ALVES, S. B. Controle microbiano de insetos. Piracicaba: Fundação de Estudos Agrários Luiz de Queiroz p. 447-480. 1998.

WHO. World Health Organization. Resistance of vectors of disease to pesticides. Fifth report of the WHO Expert Committee on Vector Biology and Control. Technical Report Series 655, 1980.

ZONTA, E. P.; MACHADO, A. D.; SILVEIRA JUNIOR, P. Sistema de análise estatística para microcomputadores: SANEST. UFPEL, Pelotas, 1984. 